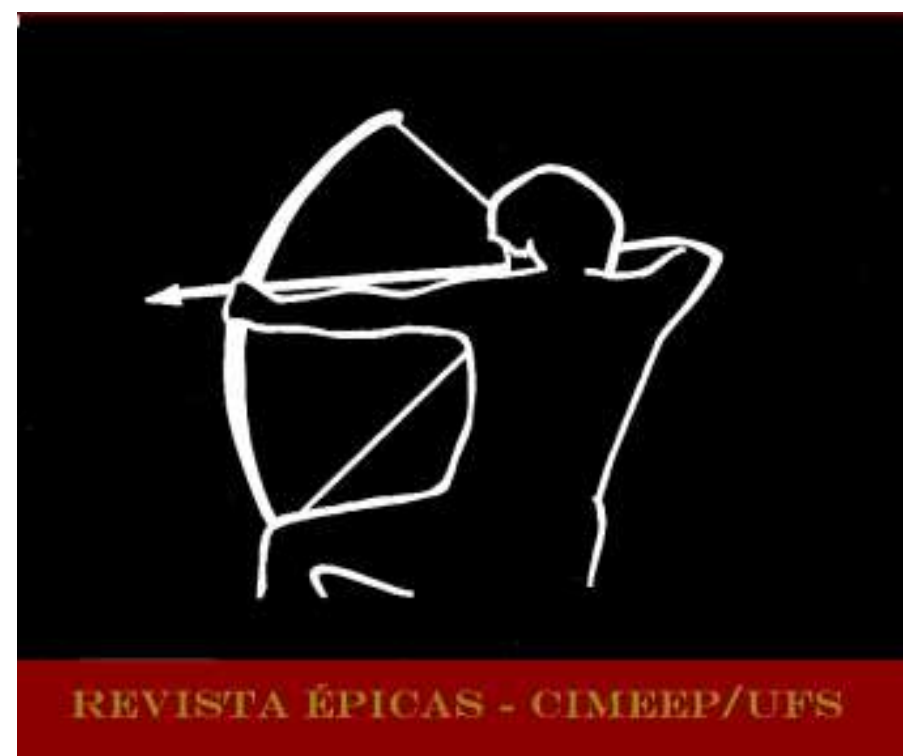

BORNAND, Sandra. Boubou Ardo Galo, uma interpretação songaizarma. Trad. Antonio Marcos Trindade e Christina Ramalho. In: Revista Épicas. Ano 4, N. 7, Jun 2020, p. 1-18. ISSN 2527-080-X.

\title{
BOUBOU ARDO GALO, UMA INTERPRETAÇÃO SONGAI-ZARMA ${ }^{1}$
}

\author{
BUBU ARDO GALO, A SONGHAY-ZARMA READING²
}

\author{
Sandra Bornand ${ }^{3}$ \\ CNRS, COMUE Sorbonne Paris Cité, \\ INALCO-CNRS, UMR 8135 LLACAN \\ (Linguagem, Línguas e Culturas da África Negra)
}

RESUMO: Este artigo dialoga com o de Christiane Seydou, por confrontar as interpretações do mesmo personagem histórico-lendário: Boubou Ardo Galo, por griots de diferentes culturas e idiomas - Fulas ${ }^{4}$ do Mali e Zarma do Níger. Na área fula, a epopeia de Boubou Ardo Galo está na encruzilhada entre o período

\footnotetext{
${ }^{1}$ Artigo publicado na Le Recueil Ouvert, com título original: "Boubou Ardo Galo, une interprétation songhay-zarma". Referência original completa: BORNAND, Sandra. Boûbou Ardo Galo, une interprétation songhay-zarma. In: Le Recueil Ouvert [En ligne], mis à jour : 11/10/2017, URL : http://ouvroir-litt-arts.univ-grenoble-alpes.fr/revues/projetepopee/273-boubou-ardo-galo-une-interpretation-songhay-zarma.

${ }^{2}$ Registro da autora em rodapé do artigo original: "Este texto se beneficiou dos conselhos e revisões de Boubé Saley Bali, Elara Bertho, Florence Goyet, Jean-Luc Lambert e Christiane Seydou. Meus agradecimentos a todos".

${ }^{3}$ Sandra Bornand é pesquisadora do LLACAN (Linguagem, Línguas e Culturas da África Negra, UMR 8135). Antropóloga linguista, trabalha em práticas linguísticas, inclusive literárias, nas sociedades songai-zarma (Níger), a fim de entender o social através da linguagem. Entre seus trabalhos sobre a epopeia estão: Le Discours du griot généalogiste chez les Zarma du Niger. Paris: Karthala, 2005. Além dos artigos: : Une narration à deux voix. Exemple de coénonciation chez les jasare songhay-zarma du Niger. In : Cahiers de littérature orale 65 "Autour de la performance", 2009, p. 3963. Mis en ligne le 01 mars 2013, consulté le 11 décembre 2016. http://clo.revues.org/1104; DOI : 10.4000/clo.1104 ; Hommage aux Peuls ou comment dire l'indicible en pays zarma. In : BAUMGARD, Ursula \& DERIVE, Jean (éd.). Paroles nomades. Écrits d'ethnolinguistique africaine. Paris : Karthala, 2005, p. 319-340 ; Niger : une étude de l'idéologie de l'ostentation dans la société zarma 'traditionnelle' et moderne : l'exemple des relations entre nobles et jasare. In : Nouveaux Cahiers de l'IUED, 15, 2004, p. 87-105.

${ }^{4}$ Segundo Xina Smith de Vasconcellos, tradutora da biografia de BÂ (Amadou Hampâté. Amkoullel, o menino fula. 3a ed. São Paulo: Palas Athena: Acervo África, 2013, p. 18), a etnia africana, designada pelo termo francês peul, costuma ser traduzida na literatura inglesa como fulani, na francesa como peul e na de língua portuguesa como fula. Esta tradução adota, na esteira de Vasconcellos, esta última forma, fula, para designar essa etnia africana, em respeito ao seu uso corrente em língua portuguesa. (NT).
} 
pré-islâmico e a era da diina (Estado Islâmico). O personagem condensa toda a ambiguidade dessa situação e seu imenso sucesso é completamente paradoxal. Boubou de fato incorpora resistência ao Islã e lealdade ao Pulaaku (ideologia "identitária" fula), e ainda assim seu sucesso não enfraqueceu entre os Fulas, notórios propagadores do Islã no Sahel. Na área zarma, essa epopeia faz parte das chamadas histórias de "distração", distintas daquelas relativas aos verdadeiros heróis zarma, cuja função é exaltar seus descendentes. Na história de Boubou Ardo Galo, contada pelos griots zarma, a oposição do personagem ao Islã se confunde com sua luta contra os Fulas, representados aqui pelos principais responsáveis pela implantação do Islã nessa região.

Palavras-chave: Contexto radiofônico; epopeia fula; zarma griot; Níger; reinterpretação ideológica.

ABSTRACT: The articles by Christiane Seydou and Sandra Bornand review the interpretations of one particular historical-legendary character: Bubu Ardo Galo, by griots of different cultures and languages Fulani of Mali and Zarma of Niger. In the fulbe area, the epic of Bubu Ardo Galo is at the turning-point between the pre-islamic period and the time of the dina. The character embodies all the ambiguity of this situation, and its immense success is completely paradoxical. Boubou in fact embodies resistance to Islam and loyalty to pulaaku (the typical "Fulani ideology") yet his success remains undiminished among the Fulani who are known for spreading Islam in the Sahel. In the Zarma area this epic is part of the so-called tales "of distraction" (faakaaray deede), distinct from those that relate to the Zarma heroes whose function is to exalt their descendants. In Bubu Ardo Galo's account, as told by the Zarma griots, the character's opposition to Islam is confused with his struggle against the Fulani, embodied here by those most responsible for the spread of Islam in the area.

Keywords: Radio context; Fula epic; zarma griot; Niger; ideological reinterpretation.

\section{Preâmbulo relativo aos artigos de Christiane Seydou e Sandra Bornand}

A presença de um mesmo herói na produção épica de duas populações africanas distintas já é questionável. Ainda mais quando, estudando a gesta desse herói - Boubou Ardo Galo -, em sua própria sociedade de origem, os Fulas, descobrimos que ele apresenta uma ambivalência assumida, uma vez que incorpora resistência ao Islã, em uma população que inclui os últimos fundadores das teocracias islâmicas na África Ocidental, e, no entanto, apesar disso, continua a ser celebrado pelos griots até hoje. Outra curiosidade: ele emigrou para os relatos épicos de uma população, os Songai-Zarma, a qual, precisamente, teve que lutar contra a islamização imposta pelos Fulas.

Ao estudar esse caso, parece que o cerne do problema está principalmente no público em questão. Na área fula de onde ele vem, esse personagem, que está na encruzilhada do período pré-islâmico e da era da diina (Estado Islâmico), encarna toda a ambiguidade dessa situação - a resistência ao Islã e a lealdade ao pulaaku (ideologia "identitária" fula) se confundem nessa figura - o que, sem dúvida, explica seu tratamento paradoxal e celebridade ininterrupta entre os Fulas, notórios propagadores do Islã no Sahel. Na área songai-zarma, essa epopeia faz parte das chamadas histórias de "distração", distinta daquelas concernentes aos verdadeiros heróis songai ou zarma, os quais têm a função de exaltar seus descendentes, e a oposição do personagem ao Islã se confunde com a luta dos Zarma contra os Fulas, 
representados aqui pelos principais responsáveis pela implantação do Islã nessa região: os Fulas de Macina e El Hadj Omar, o "conquistador toucouleur".

O tratamento que cada griot (tanto entre os Fulas quanto entre os Zarma) dá à apresentação do personagem - durante vários episódios em que, diante de situações conflitantes, ele conhece destinos contraditórios - sugere que as diferentes orientações adotadas para cada versão são altamente dependentes do público-alvo; o que, a propósito, revela um fato determinante em sociedades com tradição oral ainda operando ativamente na transmissão do patrimônio literário africano.

Destinadas ao público fula, as versões mantêm, não sem uma certa confusão, Boubou Ardo Galo em seu status de personagem icônico, próprio a todo herói épico, como a personificação do pulaaku (ou seja, como aquele que encarna o código de conduta do povo fula); uma vez que o papel sociocultural das performances épicas ainda é reviver no auditório, através da forma textual, vocal e musical desses relatos épicos, um reconhecimento exaltado dos valores que constituem sua unidade e solidariedade.

Destinadas ao público zarma, as versões, lidando com um herói que não pertence à população-alvo, permitem liberdade de tratamento, impossível quando o personagem heroico é songai ou zarma. As transmissões por rádio, em particular, destinadas a um público indiferenciado, têm duas vantagens: por um lado, podem adotar um tratamento menos orientado para a exaltação da identidade (como são as histórias de ancestrais ou guerreiros), evitando assim o risco de criar tensão dentro de uma audiência que é impossível de identificar e inacessivel; por outro lado, podem mudar ou até transpor a situação épica para crises narrativas contemporâneas: crises sociais, religiosas ou políticas; e o caráter de Boubou Ardo Galo, a encarnação do pulaaku é, portanto, particularmente bem-vinda por despertar o sentimento de independência, quando o Níger ${ }^{6}$ experimenta tensões com a Líbia e com o estabelecimento de um islamismo wahhabi (ortodoxo).

A epopeia de Boubou Ardo Galo também é contada no Níger para um público de língua songai. É interessante, então, perguntar-se por que esse público aprecia esse canto que coloca em cena somente personagens do povo Fula.

\footnotetext{
${ }^{5}$ Segundo nos informou Bornand, a partir de Seydou, os "toucoleur" são um subgrupo fula, que fala uma variante da língua, o Pulaar.

${ }^{6} \mathrm{O}$ artigo aborda o contexto histórico e literário do Níger (República do Níger, capital Niamey, gentílico: nigerino/a). Não confundir com a Nigéria (República Federal da Nigéria, capital Abuja, gentílico: nigeriano/a). (NT).

7 Obviamente, mantemos para cada item a grafia específica da área considerada (exemplo: Chêkou Âmadou entre os Fulas e Sékou Amadou entre os Songai Zarma, Boubou com ou sem sotaque ...). (Nota da autora).
} 
Com efeito, eu identifiquei nada menos do que quatro griots que contaram essa história em língua songai ${ }^{8}$. Também foi transmitido nos anos 80 pela rádio nacional nigerina e continua sendo transmitido atualmente pela rádio privada.

Para este trabalho, estarei interessada na versão mais conhecida, produzida para o rádio por Djado Sékou, um jasare (historiador griot e genealogista zarma) famoso por ter tornado a narração no rádio sua especialidade. Para concluir minha análise, no momento oportuno, compararei essa versão com outras duas de outro jasare, Djéliba Badjé: uma versão completa, que eu mesma gravei; a outra foi feita para o rádio, mas cobre apenas a segunda parte da epopeia contada por Djado.

\section{Elementos de contextualização}

Para que possamos entender esse fenômeno, gostaria de apresentar em poucas palavras o Songai-Zarma e as relações que eles têm com os Fulas.

Cerca de $22 \%$ da população nigerina faz parte da chamada songai-zarma-dendi ${ }^{9}$, a segunda maior população do Níger, atrás dos Hauçá. Embora reivindiquem em seus discursos uma aristocracia de origem diferente, Songai, Zarma e Dendi compartilham uma estrutura social idêntica, um certo patrimônio cultural e uma mesma língua ${ }^{10}$.

\subsection{Historicamente}

Embora a origem dos Songai e dos Dendi seja bem conhecida, os Zarma são descritos como "um povo que surgiu por mutação das margens ocidentais do Império Songai, um dia no século XVI, com (fato singular) sua história, sua religião, suas particularidades"11. Após um conflito com os Fulas ${ }^{12}$, eles teriam migrado para as regiões que atualmente ocupam o oeste do Níger. Chegaram pela primeira vez a Sargane, ao norte da capital Niamey, e depois continuaram sua migração para o sul, eventualmente ocupando uma vasta terra de cerca de $60.000 \mathrm{~km} 2^{13}$. Os Zarma são cercados ao norte pelos Tuaregues, ao noroeste pelos Songai, ao leste pelos Hauçá, ao sudoeste pelos Gourmantchés e Fulas e ao sul pelos Dendi.

\footnotetext{
8 Falo aqui da "língua songai", como os linguistas geralmente fazem para designar o continuum ou a "família de línguas" agrupando as diferentes línguas songai e zarma. No Níger, a maioria dos linguístas fala da "língua songaizarma" para evitar qualquer debate de identidade.

${ }^{9}$ Sobre o conjunto songai-zarma-dendi, ler: OLIVIER DE SARDAN, Jean-Pierre. Unidade e diversidade do conjunto songai-zarma dendi. In: Assentamento e migrações. Anais da primeira conferência internacional, de 26 a 29 de setembro de 1995. Parakou e Niamey: CEHLTO, 2000, p. 139.

10 Sobre essa unidade linguística e sobre os elementos da variação, ver: BORNAND, Sandra. Vamos falar sobre Zarma. Uma língua do Níger. Paris: L'Harmattan, 2016.

11 MOUNKAïLA, Fatimata. Mito e história na gesta de Zabarkane. Niamey: CEHLTO, 1989, p. 5.

12 Outras versões se referem aos Tuaregues e não aos Fulas.

13 Se Zarmaganda (literalmente "terra de Zarma") é a terra de escolha, Zarmataray (literalmente "país de Zarma, sendo/condição de Zarma") é a terra da expansão.
} 
No século XVII, os Fulas, que vieram, segundo Boubé Gado ${ }^{14}$, de Macina, estabeleceramse pela primeira vez de maneira pacífica no país zarma (Zarmataray), todavia, desde o advento de Ousmane Dan Fodio no país hauçá (1804), realizaram saques contra o Zarma e tomaram o poder no leste. A partir de então, a região viveu em guerra até a chegada dos franceses no final do século XIX. À beira do rio, a situação era diferente: Zarma e Fulas viveram em paz, principalmente por causa de Alfa Mahamane Diobbo, marabu (ou seja: líder espiritual islâmico) fula de Say, cuja autoridade moral e espiritual foi reconhecida pelos dois lados. Alguns chefes zarma nessa área ocasionalmente se juntaram aos Fulas para combater outros chefes zarma no leste ${ }^{15}$.

De qualquer forma, os Fulas foram os agentes da islamização dos Songai-Zarma. Atualmente, eles compartilham um território comum com os Zarma ${ }^{16}$; contudo, conflitos recorrentes permanecem (especialmente no leste). De fato, se os Fulas são principalmente pastores, os Zarma são, em sua maioria, agricultores, e nem sempre é fácil atravessar os rebanhos dos primeiros ${ }^{17}$.

\subsection{Linguisticamente}

No Níger, songai-zarma (como é chamado no Níger) e fula são considerados idiomas nacionais (assim como hauçá e sete outras línguas) aos quais é adicionado o francês, que é o idioma oficial.

Embora existam muitos empréstimos recíprocos entre songai e fula, essas duas línguas não têm características comuns: a primeira é uma língua com sistema tonal (com dois níveis e quatro tons), do tipo isolante, com morfologia fraca, enquanto a segunda é, ao contrário, uma língua aglutinativa, sem tons.

No Níger, na maioria das vezes são os Fulas que adotam o idioma dos outros falantes da região em que vivem para interagir, a tal ponto que acontece - embora não muito frequentemente, porém numa constância suficiente para que isso seja observado - de filhos de fulas não falarem mais a língua de seus pais. Se os Songai-Zarma, que vivem entre os Fulas, conseguem entender e falar a língua destes últimos, eles geralmente recorrem a língua deles apenas como último recurso, quando seu interlocutor não fala songai ${ }^{18}$.

\footnotetext{
${ }^{14}$ GADO BOUBÉ, Le Zarmatarey. Contribuição para a história das populações entre o Níger e Dallol Mawri. Niamey: Estudos nigerianos 45, 1980.

15 Para mais detalhes sobre a história da região, ler: IDRISSA, Kimba. Guerras e sociedades. As populações do Níger ocidental no século XIX e suas reações à colonização (1896-1906). Niamey: Estudos nigerianos 46, 1981.

${ }^{16}$ Existem até casamentos mistos entre Fulas que vivem em Zarmataray e Zarma, a partir do rio.

17 Esses conflitos são particularmente intensos durante a transumância sazonal que coincide com a estação da colheita. No Boboye, a rivalidade é ainda mais alimentada pelas consequências dos conflitos ocorridos no século XIX entre os Fulas e Zarma.

${ }^{18}$ Isso precisa ser verificado; essas são observações contextuais e não uma pesquisa sociolinguística.
} 


\subsection{Socialmente}

As sociedades songai-zarma, muito hierárquicas, são marcadas por uma separação entre homens livres e escravos. Embora a escravidão não exista mais atualmente, a discriminação social contra os descendentes de cativos continua ${ }^{19}$.

Essa dicotomia se torna tricotômica quando levamos em conta os jasare (griots genealogistas e historiadores de origem soninké, considerados mestres-griots). Não pertencendo nem ao grupo de "nobres" nem ao de "cativos" 20 , esses griots se diferenciam dos outros griots-quémandeurs ( $\eta$ waarayko), especialmente por sua origem soninké, que thes confere um aprendizado longo e muito estruturado, capacitando-os à enunciação de discursos históricos e ao domínio do alaúde de três cordas (moolo $)^{21}$. Os jasare colocam suas habilidades discursivas e memoráveis a serviço de homens livres; seu repertório, particularmente rico e variado, inclui vários gêneros discursivos: genealogias (kaayi ceeyan: literalmente "chama dos ancestrais"), louvores (zamu), epopeias (wangaari deede, literalmente "relatos de guerreiros"), relatos de ancestrais (kaayi deede), relatos de distração (faakaaray deede).

\section{O interesse surpreendente dos Songai-Zarma pelas epopeias fulas}

Combinando investigação etnográfica e análise de discurso, pude listar várias razões que justificam esse interesse dos Songai-Zarma pelas epopeias fulas. Primeiro, como vimos, os Songai-Zarma sempre mantiveram relações com os Fulas, seja na região de origem (no que hoje é a República do Mali) seja em seus territórios atuais.

Do ponto de vista das representações sociais, os Fulas constituem, aos olhos da etnia Songai-Zarma, um povo próximo e distante. Eles são próximos pela localização geográfica, porque compartilham o mesmo território por alguns séculos. Essa proximidade gera algumas semelhanças entre eles, especialmente quando abordamos certos traços sociais, também

\footnotetext{
19 Sobre essa dicotomia, ler: OLIVIER DE SARDAN, Jean-Pierre. As sociedades Songai-Zarma (chefes, guerreiros, escravos, camponeses...). Paris: Karthala. 1984; sobre a perpetuação da ideologia aristocrática nos círculos econômico e político, cf. KOMLAVI HAHONOU, Eric. Cultura política, escravidão e descentralização. A vingança política dos descendentes de escravos no Benin e no Níger, In: Política Africana 111, 2008, p. 169-186.

${ }^{20}$ As designações "nobre" e "cativo" são do francês africano e correspondem a "homem livre" (burcin) e "escravo" (banna).

21 Sobre os diferentes tipos de griots, cf. BORNAND, Sandra. O Discurso do Griot genealogista entre os Zarma do Niger. Paris: Karthala, 2005.
} 
compartilhados, é verdade, com outros povos da África Ocidental: além da mencionada dicotomia entre homens livres e escravos, acima mencionada, e da presença de um griot genealogista e historiador, mencionarei essa característica essencial, que é o sentimento de modéstia, também chamado de "vergonha" (haawi em zarma), que impõe enfaticamente o total controle das emoções. Esse sentimento, altamente valorizado, tanto entre os Songai-Zarma quanto entre os Fulas ${ }^{22}$, distingue o homem livre, que, como se diz, sem a sentir, "conhece a vergonha" do escravo (ou de seus descendentes).

A alteridade reside no fato de serem dois povos com origens e história distintas: os criadores fulas, geralmente nômades, opõem-se aos agricultores sedentários e aos Estados fulas do século XIX, que são islamizados, enquanto os pequenos chefes songai-zarma, freqüentemente, são refratários ao Islã. Isso explica a representação ambivalente que os SongaiZarma ainda hoje têm dos Fulas:

Ao mesmo tempo, respeitados, valorizados ou admirados (por causa de sua antiga hegemonia política: será fácil dizer dos aristocratas fulas que eles são "mais" nobres do que qualquer outra pessoa; também por causa do papel que desempenharam na propagação do Islã) e ao mesmo tempo alvo de zombaria ou sarcasmo, seja por causa de seu modo de vida diferente (tanto como pastores de ovelhas, quanto como pastores da religião), seja porque são considerados como tendo um caráter enganoso e desonesto ${ }^{23}$.

No entanto, é provavelmente nesse contraste entre semelhança e alteridade que reside o interesse dos griots songai-zarma pelas epopeias fulas. Os Fulas estão próximos o suficiente geograficamente e por seus valores - para serem familiares aos ouvintes, e essa proximidade torna a moral disseminada em histórias cujos heróis, tempo e lugar são de outros lugares, dignas de crédito. Todavia, eles também são diferentes o bastante para que se possa permitir uma liberdade de tom que o griot não permitiria em epopeias que evocam heróis songai-zarma.

Essa liberdade também é possível, porque o objetivo perlocucionário das histórias varia de acordo com o tipo de herói encenado. Assim, os relatos dos quais os heróis são songai ou zarma, contados a seus descendentes, são chamados de wangaari deede "relato do guerreiro" ou kayayi deede "relato dos antepassados", ao contrário - em resumo - dos contos cujos heróis são estrangeiros, os quais são considerados faakaaray deede, ou "relatos de distração"24.

Essa mudança de gênero, às vezes para a mesma história, implica uma mudança no objetivo perlocucionário; quando o griot relata as façanhas de um herói zarma ou songai, ele procura vincular seus descendentes ao ancestral deles e, desse modo, provocar um sentimento

\footnotetext{
22 Isso faz parte deste pulaaku de que Christiane Seydou fala.

23 Olivier de Sardan, J-P., "Unidade e diversidade ...", op. cit., p. 139.

24 BORNAND, Sandra. Le Discours ..., op. cit. ; BORNAND, Sandra. Chamando os ancestrais: práticas e memória discursiva entre os Zarma do Níger. In: Textual 56, 2009, p. 107-137.
} 
de exaltação: lembrá-los de onde eles vêm causa uma forte emoção e deve levar os ouvintes a adotar um comportamento digno de seus ancestrais (bravura, generosidade etc.), já que, em essência, eles herdaram essas qualidades. O "relato de distração", por outro lado, pretende ser recreativo, mesmo que retenha sua função de ensinar e incentivar o bom comportamento social. Suas características a aproximam do conto (jandi), contudo, ao contrário desse, a "história de distração" mantém um caráter histórico e é percebida como verdadeira, devido, em especial, à sua narração por griots.

Há, no entanto, outra razão para optar por contar a história de um herói fula. A ética do griot não lhe permite relacionar o que provavelmente criaria tensões em seu público songaizarma. Portanto, ele deve adaptar constantemente seu discurso, ou mesmo censurar certas partes dele, dependendo da identidade de seus ouvintes, a fim de controlar o risco de discórdia que ele poderia representar para a comunidade. Um provérbio zarma não diz: "Um mau discurso é como fogo no mato: você sabe quando ele começa, porém nunca quando pára"? Ora, a epopeia que nos interessa foi gravada e transmitida no rádio. Diante de um público anônimo, que é impossível identificar, o griot geralmente opta por "relatos de distração" 25 , porque são mais consensuais, a ponto de os jovens Zarma - que têm apenas um conhecimento radiofônico dos relatos dos griots - pensarem que não há épopeias em sua cultura.

Essa escolha de um relato cujos heróis são estranhos às pessoas que formam o público ouvinte é, assim, uma estratégia do griot que visa distanciar a narrativa histórica para remover apenas sua substância - sua moral - sem arriscar prejudicar a harmonia social às vezes frágil.

\section{A história de Boubou Ardo Galo, do contexto histórico à performance}

A epopeia de Boubou Ardo Galo interessa especificamente ao público songai-zarma, porque fala da islamização da região e das revoltas produzidas na sociedade fula pelo confronto entre os valores da sociedade pré-islâmica e aqueles que trouxe a nova religião. A região songaizarma passou por uma crise idêntica e permanece preocupada, no momento da narração, com as questões da articulação entre a cultura "tradicional" e a prática religiosa. Contá-la como uma história que afeta os Fulas - agentes da islamização dos Songai-Zarma - o épico se torna, portanto, um recurso particularmente eficaz em chamar a atenção de seu público para o que está em jogo.

O país songai-zarma sofreu várias ondas sucessivas de islamização. Se o Islã foi introduzido pela primeira vez no país songai no século $X$ pelos comerciantes, sua posição

25 Os únicos relatos sobre Songai e Zarma contadOs no rádio dizem respeito a Askia Mohammed, o ancestral fundador da dinastia songai Maïga, e Mali Béro, o ancestral mítico dos Zarma. A história de um guerreiro zarma que lutou no país de Gourounsi (agora Gana) foi gravada no rádio, porém raramente é transmitida. 
permaneceu marginal (até o início do século XIX e sob a liderança de grandes líderes religiosos islâmicos fulas, os marabus, no país Songai-Zarma) ${ }^{26}$. Firmemente implantado nos principados localizados às margens do rio ou nas áreas de trânsito, o Islã era uma minoria nas outras regiões, que permaneceram fortemente apegadas às religiões locais. Paradoxalmente, a colonização, que desempenhou um papel determinante na expansão do Islã, foi percebida como um fator de unidade e um meio de distinção em relação ao poder francês, e sua progressão foi tanto geográfica quanto social ("a cosmogonia, a lei, a moralidade islâmica gradualmente vão começando a permear a vida cotidiana, mesmo que isso custe uma mistura com a cultura préislâmica" ${ }^{27}$ ). Essa implantação não foi bem recebida em todos os lugares e, como J. Rouch ${ }^{28}$ relata, os locais de oração muçulmanos foram incendiados periodicamente até pelo menos a década de 1950; contudo, o Islã se tornou cada vez mais importante no território songai-zarma.

Do ponto de vista do contexto da performance, a situação das comunicações via rádio é incomum ${ }^{29}$ para um griot e ela coloca-lhe dificuldades específicas. Acostumado a falar para um público que ele identifica e ao qual ele adapta com habilidade seu discurso, a fim de respeitar seu contrato tácito de não incomodar ninguém, o griot deve aqui lidar com todos as possibilidades: os Songai-Zarma não formam uma única entidade, nem em suas relações com os Fulas, nem em seus vínculos com o Islã; além disso, essa epopeia pode ser ouvida por qualquer um que entenda o songai, inclusive pelos Fulas da região.

Essa epopeia é registrada em um contexto religioso e político tenso. Se, ao recontar, em 1987, o épico de Boubou Ardo Galo no rádio, Djado Sékou estava falando - embora as práticas pré-islâmicas persistissem - para um público muçulmano, diferentes movimentos estavam em confronto:

- A obediência sufi, a mais importante até meados da década de 1990, é representada por duas irmandades, a Qadiriyya e a Tijâniyya (respectivamente designadas no épico por Hamdallaye e Xeique El Hadj Omar);

- O movimento Izala ${ }^{30}$, de obediência wahhabi (ou seja: ao islamismo ortodoxo), confidencial nos anos 1980, desenvolveu-se rapidamente com o advento da política

\footnotetext{
${ }^{26}$ Sobre as relações entre Zarma e Fula ao longo dos séculos, ver IDRISSA, Kimba. Guerras e sociedades..., op. cit.

27 OLIVIER DE SARDAN, Jean-Pierre. As sociedades songai-zarma, op. cit., p. 274.

${ }^{28}$ ROUCH, Jean. A Religião e a magia songai. Bruxelas: Instituto de Sociologia e Antropologia Social, Edições da Universidade de Bruxelas, 1989.

${ }^{29}$ Sobre narração de griots em um contexto de rádio, ver BORNAND, Sandra. Uma narração para duas vozes. Exemplo de coenunciação entre os jasare songai-zarma do Níger. In: Cadernos de literatura oral 65 "Em torno da performance", 2009, p. 39-63. Online, 01 de março de 2013, acessado em 11 de dezembro de 2016. http://clo.revues.org/1104.

30 "Izala é um diminutivo usado para Izala bid'a wa iqamatul Sunna, que inicialmente era uma organização cujo objetivo era a restauração da Sunna do profeta Muhammad, removendo todas as 'inovações dignas de culpa' das práticas islâmicas. Como tal, ela se destacou particularmente por sua oposição às irmandades sufis." (SOUNAYE , Abdoulaye. A 'boate' islâmica: CD e DVD no coração da re-islamização da Nigéria. In: Ethnographiques.org, edição
} 
multipartidária no início dos anos 1990, devido a um afrouxamento do controle estatal sobre as forças, políticas ou religiosas, capazes de minar sua autoridade.

A coexistência entre os Tijâni e os Izala não é fácil, e conflitos recorrentes foram observados na década de 1980.

Do ponto de vista político, essa epopeia foi contada alguns meses antes da morte do general Seyni Kountché, no poder desde seu golpe militar em 1974. Se o general havia abordado taticamente os países árabes por causa de sua religião comum, ele queria manter o controle das autoridades religiosas, porque via nos movimentos muçulmanos possíveis vetores de rebelião. É preciso dizer que o período foi instável para a ditadura nigerina, que estava enfrentando tensões com o regime líbio de Kadhafi, o qual teria financiado vários golpes abortados. É nesse contexto que a epopeia de Boubou Ardo Galo foi gravada e transmitida pela "Voz do Sahel", a estação de rádio oficial, transmitida em todo o país ${ }^{31}$.

Além disso, há relações tensas entre Djado Sékou, o narrador, e Seyni Kountché, o qual anteriormente já havia censurado um de seus épicos, o de El Hadj Omar. Considerando um tanto vulgar a parte sobre Boubou Ardo Galo, o general pediu ao griot que fornecesse uma versão mais adequada, no que foi atendido pelo narrador ${ }^{32}$. Kountché também criou, da mesma forma como havia feito em relação à religião, a "Associação de Griots do Níger", a fim de exercer controle sobre esse grupo socioprofissional.

\section{Uma reinterpretação ideológica}

Para mostrar como os griots songai-zarma reinterpretam "a instauração de uma nova ${ }^{33}$ ideologia" em Macina, aqui está um breve resumo do épico na versão de Djado Sékou ${ }^{34}$.

Pensando que poderia converter Boubou Ardo Galo, o último chefe não muçulmano da região, o chefe fula de Macina, Sékou Amadou deu a ele sua filha Takaldé Waldé em casamento. O guerreiro aceita a garota, todavia, por bravura, continua sendo ainda mais incrédulo, e Sékou Amadou se vê forçado a declarar guerra contra ele. Essa atitude de Sékou Amadou não será boa para ele, porque Boubou Ardo Galo o derrotará e o humilhará, oferecendo-o como escravo a seu griot e o proibirá de praticar sua religião. Sua provação irá durar dois anos, até que Boubou Ardo Galo finalmente resolva libertá-lo.

\footnotetext{
22, maio de 2011: As ferramentas de um Islã em mudança. Re-islamização e moralização no sul do Saara, número 22 - maio de 2011, nota 1, http://www.ethnographiques.org/2011/Sounaye).

${ }^{31}$ Atualmente, as epopeias são transmitidas sobretudo em rádios privadas.

320 resultado é precisamente a versão do épico analisada neste artigo.

33 Ver o artigo de Seydou já citado anteriormente.

${ }^{34} \mathrm{O}$ épico contado por Djéliba varia apenas em alguns detalhes. Apenas os levantarei na medida em que sejam significativos para o meu propósito.
} 
Para vingar o pai, Takaldé Waldé empurra o marido para a guerra contra o único chefe que poderia derrotá-lo: El Hadj Omar, o grande guerreiro muçulmano toucouleur. Boubou Ardo Galo o enfrenta, apesar de uma profecia que prevê derrota para ele; o que efetivamente acaba acontecendo com sua morte na batalha. El Hadj acaba capturando Hamdallaye, capital de Macina, e decapita Amadou Amadou, filho de Sékou Amadou, culpado de ter recebido o guerreiro "pagão", seu cunhado, que se refugiara em sua casa.

El Hadj, em seguida, faz uma peregrinação a Meca. Lá, ele mostra que domina o Alcorão melhor que os árabes e revela a eles que quem dirige a oração não é outro senão seu antigo inimigo, o general francês Faidherbe. Os árabes reconhecem sua superioridade antes que ele retorne, após algumas aventuras, ao seu reino.

Nas versões contadas pelos dois griots songai-zarma, Djado Sékou e Djéliba Badjé, encontramos a ambiguidade, já descrita por Christiane Seydou, entre um apego aos valores "tradicionais" e a prática do Islã. No entanto, há duas diferenças significativas:

- Boubou Ardo Galo luta contra o estado teocrático de Hamdallaye e contra o conquistador muçulmano de Futa Toro, El Hadj Omar.

- A epopeia não para com a morte de Boubou Ardo Galo, porém continua com as aventuras de El Hadj em Medina e Meca, uma oportunidade para o narrador defender a superioridade de um "Islã negro" sobre os árabes.

Assim, os personagens de Boubou Ardo Galo e El Hadj Omar não puderam, historicamente, se encontrar. Como então entender esse anacronismo que leva a um duplo confronto?

\section{Boubou Ardo Galo, uma figura importante da resistência}

Esse artifício permite colocar Boubou Ardo Galo no centro dos dois principais eventos que perturbaram Macina no século XIX: a islamização e a queda de Hamdallaye. O anacronismo contribui para destacar uma figura de resistência e a transforma em um grande herói, tanto melhor quanto permite que Djado e Djéliba proponham uma comparação explícita entre Boubou Ardo Galo e El Hadj Omar, o último grande conquistador muçulmano da África Ocidental. Citemos Djado:

A esposa de Boubou Ardo Galo] olhou ao redor do mundo e viu que seu marido só era correspondido por El Hadj Omar do Futa [...]" (Djado, v. 580)

Esta é a história de Boubou Ardo Galo e El Hadj Omar do Futa" (v. 1506).

Observamos, ao longo da epopeia, outras semelhanças entre esses dois personagens:

- ambos são elogiados pelo narrador griot;

- cada um possui no relato um griot de sua própria religião; 
- ambos saem vitoriosos de pelo menos um confronto (Boubou contra Sékou Amadou, El Hadj contra Boubou e Amadou Amadou, às vezes confundidos na epopeia com Sékou Amadou, seu pai).

Os líderes de Hamdallaye - Sékou Amadou e Amadou Amadou - não são elogiados pelo narrador, nenhum griot é mencionado ao lado deles e eles são derrotados por Boubou Ardo Galo e El Hadj Omar. Além disso, nem Djado nem Djéliba Ihes dedica algo, em seu repertório épico. Pode-se dizer que esses dois líderes aparecem, em ambas as versões, como personagens secundários, em relação aos heróis principais. São os narradores que, valorizando-os, fazem com que eles possam desempenhar seu papel com mais força: os líderes de Hamdallaye são definidos como "santos" cuja conduta é impecável e heroica, mesmo que isso acabe por levá-los à derrota e à morte.

Todavia, dedicando explicitamente a epopeia a Boubou Ardo Galo ${ }^{35}$ e não a El Hadj Omar, por muito presente que este esteja na história, Djado e Djéliba glorificam é a Boubou Ardo Galo, considerado por eles um guerreiro resistente, representante do espírito de independência. Essa é uma oportunidade para esses grupos reativarem valores familiares aos ouvintes de língua songai. Os Fulas são exemplos que eles invocam, quando se trata de falar sobre autocontrole, senso de honra ou independência de espírito, três valores também importantes para o Songai-Zarma ${ }^{36}$.

Mais ainda, a epopeia de Boubou Ardo Galo deve ser reinterpretada à luz da situação nigerina e das questões que a atravessam no momento da narrativa, em particular a articulação entre a cultura "tradicional" e a religião muçulmana.

Quando um griot conta uma epopeia ou um relato de um ancestral de um de seus descendentes, é sempre necessário estabelecer o elo entre as gerações e mostrar sua continuidade, apesar da ruptura causada pela colonização: "Se não fosse pela época dos Brancos, ele seria capaz dos mesmos gestos que seu antepassado", sentencia o griot. Essa afirmação é uma maneira de reafirmar que, nos países songai-zarma, herdamos poder como herdamos qualidades, mesmo que algumas delas - como bravura na guerra - não sejam mais expressas atualmente, ainda que seja possível expressá-las de forma diferente ${ }^{37}$.

Assim como a colonização, a islamização trouxe uma profunda ruptura na sociedade songai-zarma e, embora o griot não diga: "Se não fosse pela era muçulmana", os ouvintes também interpretam a epopeia de Boubou Ardo Galo nos seguintes termos: há claramente um

\footnotetext{
${ }^{35}$ Ao mencionar seu nome no início e no final da narração, bem como pelos elogios que lhe são feitos e pela descrição de sua genealogia.

36 Sobre as representações dos Fulas entre os Songai-Zarma, ver BORNAND, Sandra. Le Discours ..., op. cit.

37 Para uma análise dos discursos dos griots e das relações entre enunciador e enunciadores, ibidem.
} 
antes e um depois da islamização. Esse pressuposto - "se não fossem os novos tempos" - não apenas revela uma ruptura entre dois mundos distintos por suas referências; ele também nos mostra uma continuidade, a dos atos de resistência e bravura, já que cada um dos dois heróis se rebela contra o que os outros procuram impor: Boubou Ardo Galo enfrenta o Islã do povo de Hamdallaye e El Hadj Omar luta contra os árabes que se atrevem a escrever que existem dez mil pessoas semelhantes a ele em Meca.

Desse modo, como a comparação de Boubou Ardo Galo com El Hadj Omar reforça o caráter heroico do guerreiro de Macina, o inverso - a comparação de El Hadj com Boubou Ardo Galo - mostra continuidade nesses dois heróis fulas: sua recusa de dominação externa. Porém, com uma nuance: El Hadj Omar concorda em servir a Deus, o que Boubou Ardo Galo sempre rejeitou (isso não o faz dizer que o Islã é uma "prática de escravos"?).

Esses dois personagens aparecem, portanto, como figuras de resistência. É dessa maneira enfática que suas imagens ressoam no momento da narrativa. O próprio governo apela ao espírito de independência dos nigerianos, mesmo quando o país está passando por um período de instabilidade política e religiosa significativa: repercussões da violência religiosa no norte da Nigéria ${ }^{38}$, repetidas tentativas de golpe de Estado (pilotadas, como se sabe, por Kadhafi ${ }^{39}$ ), temores de uma intervenção francesa ${ }^{40}$ contra o regime do general Kountché, que mostra hostilidade tanto ao modelo ocidental quanto ao líbio.

Essa continuidade entre os dois guerreiros também é explícita em outro ponto importante: a presença de um griot ao seu lado; um griot que permanece o tempo inteiro à sua disposição, porque se o griot de Boubou Ardo Galo encoraja seu mestre a práticas nãomuçulmanas, o segundo, por sua vez, acompanha El Hadj Omar em sua jihad e em sua peregrinação a Meca. Sabendo que Seyni Kountché era cauteloso com os griots, especialmente sabendo que eles eram sempre mais contestados pelos líderes religiosos muçulmanos, os marabus, podemos ver nessa presença exibida a vontade do griot de tornar seu papel essencial e, em particular, de mostrar que é "útil" ao Islã: ele não é o companheiro de quem liderou a jihad na África Ocidental, de quem demonstrou sua superioridade sobre os sábios de Meca? A transmissão da epopeia via rádio torna-se, desse modo, uma tribuna.

\footnotetext{
38 O movimento Izala foi criado no norte da Nigéria em 1978 e seu discurso circula entre esses dois países, principalmente através da Rádio Karuna (rádio do Norte da Nigéria nas línguas hauçá, fula, kanuri e árabe), onde o pregador se posiciona como o principal oponente da Tijâniyya e Qadiriyya. Para mais detalhes, consulte: BRIGAGLIA, Adera. A Rádio Kaduna Tafse (1978-1992) e a Construção de imagens públicas de estudiosos muçulmanos na mídia nigeriana. In: Revista de Estudos Islâmicos 27, 2007, p. 173-210.

${ }^{39}$ Sobre as tensões com a Líbia, ver: GRÉGOIRE, Emmanuel. Tuaregues do Níger. O destino de um mito [1981]. Paris: Karthala, 2010.

40 Sobre a história do Níger, ler a edição número 38 da Política Africana dedicada ao Níger, coordenada por Raynaut, Claude e Robert Buitenhuijs e intitulada Níger: Crônicas de um Estado, Política Africana 38, junho de 1990, bem como o artigo: VAN WALRAVEN, Klaas. Operação Soma: A Conexão Francesa e o golpe de estado de Seyni Kountché no Níger em abril 1974. Tradução Alice Judell. In: Política Africana 134, 2014, p. 133-154.
} 
De fato, fortalecidos pela progressiva islamização das populações, certos líderes religiosos muçulmanos songai-zarma, os marabus, acusam os griots de, antes da chegada do Islã ${ }^{41}$, terem pertencido aos Jâhîliyya. Como muçulmanos alfabetizados, esses chefes espirituais, os marabus, oferecem uma identidade cultural e religiosa radicalmente diferente da transmitida pelos griots. Essa competição de conhecimento e habilidades cria um antagonismo entre esses dois grupos durante as cerimônias, porque, para afirmar seu poder na sociedade songai-zarma, certos marabus (esses líderes religiosos muçulmanos) não hesitam em denegrir publicamente os griots. Para isso:

- Eles descrevem o griotismo como "atividade ociosa" e acusam os griots de viverem intimamente ligados ao povo (esse argumento tem ainda mais peso do que aquele usado pelo próprio Kountchét2);

- Eles acusam os griots de evocarem o período pré-islâmico e de serem seus representantes, certamente em menor grau que o ziima ("sacerdotes" das religiões nativas).

- Eles acusam muitos griots de ofenderem a Deus, quando louvam simples seres humanos, porém também de mentirem desavergonhadamente, ao pontuarem suas histórias de forma exagerada. Essas acusações mais recentes são ainda mais eficazes, quando são acompanhadas de ameaças ao além, como as seguintes: aqueles que persistem nesses caminhos serão desfigurados durante o Último Julgamento ou, pior, queimarão por toda a eternidade nas chamas do inferno.

Os griots, por sua vez, não se utilizam dessa política quase sistemática de difamação, uma vez que eles próprios são muçulmanos e perderiam muito crédito se mostrassem oposição declarada aos defensores do dogma ${ }^{43}$. Diante desses ataques, suas reações são diversas: entre o abandono da prática do griotismo, o abandono apenas de relatos ou as tentativas de legitimar as práticas que consideram compatíveis com Islã. Os griots que continuam praticando, usam epopeias para mostrar sua importância e legitimar sua presença, como é particularmente o caso aqui, quando o griot se representa como um ator-chave, tanto na sociedade pré-islâmica quanto na muçulmana ${ }^{44}$.

O narrador griot, portanto, procura invalidar os argumentos dos religiosos:

\footnotetext{
${ }^{41}$ Note que a versão de Djéliba, contada alguns anos depois em um período de maior tensão entre griots e marabus, é ainda mais violenta.

42 Mesmo que na verdade ele visasse mais os "falsos griots".

${ }^{43}$ Embora às vezes o façam, em particular narrando brigas entre marabus (e enfatizando a união entre os griots); ou lembrando que os marabus os criticam por eles receberem presentes que lhe são dados por sua atividade, apesar de eles, os marabus, fazerem o mesmo.

44 Paralelamente à lenda do primeiro griot, companheiro do profeta e reconhecido por Maomé como sendo tão poderoso que, pelo poder de seus louvores, o profeta poderia acordar da morte.
} 
- Ele toca os seguidores de Tijâniyya, descrevendo-se como o companheiro de um respeitado representante do Islã na África Ocidental, um santo e um Tidjani erudito, todo-poderoso e capaz de superar seu rival em Qadiriyya, além dos estudiosos árabes de Medina e Meca.

- Ele toca os Izala, com mente wahhabi (fiel ao islamismo ortodoxo), mostrando que seus colegas em Meca não conseguiram perceber que foram levados à oração por um homem incircunciso.

- Mas ele também afeta seus "clientes" em potencial, os homens livres, quando mostra que um bom griot é uma arma e proteção para quem o possui. Isso é ainda mais evidente em Djéliba, para quem a vitória sobre Boubou Ardo Galo somente fora possível com a eliminação de seu griot.

\section{A demanda pelo "Islã negro": o episódio de El Hadj nos lugares sagrados do Islã}

Essa epopeia, nas duas versões que tenho, não é apenas a de Boubou Ardo Galo; ela contém também a gesta de El Hadj Omar, a qual parece inseparável das gestas de Boûbou Ardo Galo, como se um só assumisse seu verdadeiro significado em sua associação com o outro. Há muito tempo me pergunto sobre o interesse que os griots têm em expor esses dois relatos em conjunto para nós, e em particular o que aconteceu aqui no episódio de El Hadj Omar em Medina e Meca. Desta vez, os griots anunciam contar a epopeia de Boubou Ardo Galo.

Ao articular os dois relatos e colocá-los em uma perspectiva histórica mais ampla, descobrimos caminhos interessantes. Essa epopeia mostra a passagem entre dois mundos de referência: um passado, o outro em formação, e cada um dos heróis simboliza um dos pólos. 0 primeiro, Boubou, é o "animista" que resiste ao Islã e é heroico justamente por ser o último bastião de um mundo fadado a desaparecer. O segundo, El Hadj Omar, é o conquistador muçulmano - que passou pelo Níger - e espalhou o Islã por toda a África Ocidental. Sua aura é tal que ele se mostra invencível, tanto no campo de batalha quanto no nível religioso (seu conhecimento excede em muito o dos grandes sábios). A perfeição de El Hadj Omar reflete evidentemente em Boubou Ardo Galo, porque, em última análise, não há vergonha em ser derrotado por um herói assim.

E esse personagem de El Hadj, que desmistifica os colonos franceses (ele mostra as intrigas do general Faidherbe em Meca, também este, por seu turno, um grande herói da conquista colonial), que supera os estudiosos árabes por seu conhecimento religioso, que ninguém, nem mesmo os heróis do mundo antigo, pode derrotá-lo na guerra, não é uma maneira de lembrar os "negros" (boro bi: pessoa / negro) - tantas vezes mencionados nesse 
episódio -, sua dignidade, seu orgulho e sua legitimidade, diante desses dois principais fatores de influência, a saber: o mundo ocidental e o mundo árabe?

Ao fazer uma peregrinação a Meca, El Hadj Omar faz atos de contrição e de submissão a Deus. E, como Djado Sékou menciona, não é de avião que ele empreende a jornada. Assim o verdadeiro desafio constitui originalmente o Hadj: vários meses de périplo e a incerteza de voltar vivo. Ao embarcar nessa jornada, El Hadj Omar reconhece ter pecado quando destruiu Hamdallaye e deseja receber o perdão divino por ter feito isso. Todavia, ele obterá mais: abrindo os olhos dos líderes religiosos muçulmanos, os marabus, de Meca, revelando sua falta de cultura e orgulho, ele se torna um sábio e supera em todos os pontos os wahhabis (isto é, islamistas ultraconservadores) que afirmam retornar às fontes do Islã, porém rezam por Faidherbe, um incircunciso.

A mensagem transmitida pode ser assim resumida: "nossos fundamentos são melhores que os seus", uma maneira de enviar aos crentes de língua songai uma mensagem de desconfiança em relação ao Izala (então geralmente hauçá), de obediência wahhabi (ou seja, ao islamismo ortodoxo), depois de o fundador deste, o Xeique Aboubakar Goumi, ter qualificado os sufis de "pagãos". Como se vê, as reivindicações da época e o sonho de Kountché de produzir um forte islamismo nigeriano devem ser lidos em filigrina, ou seja, percebendo-se suas tramas complexas.

\section{Conclusão}

No início deste artigo, fiz a seguinte pergunta: como o tratamento da história e sua reinterpretação ideológica entre os Fulas poderia ser objeto de relatos em outra população? 0 exemplo que escolhemos para ilustrar nos mostra como uma epopeia cujos protagonistas são heróis fora da população-alvo é interessante para os griots, especialmente quando eles falam via rádio, onde não têm acesso ao público e, portanto, não podem se adaptar a ele em tempo real.

Ao narrar uma epopeia que não diz diretamente respeito aos que o escutam, o griot não se sente mais preso em uma rede de obrigações de dizer e exaltar a linhagem; ele pode então propor regimes de pensamento contemporâneo mais inovadores, diante das crises na sociedade nigerina (tensões de identidade, geopolíticas, religiosas, sociais ou culturais). É uma questão, na epopeia estudada aqui, tanto de como despertar o sentimento de independência entre os nigerianos de língua songai (o país então experimenta tensões com seu vizinho líbio e com a França, o país que o colonizou), quanto de propor uma referência cultural específica, em particular com a demanda pelo "Islã negro" e um apelo para manter o griot no papel central que ele ocupa na sociedade. 
Essa operação de narrar o presente, por meio de um discurso considerado como "distração", é, portanto, realizada com mais eficácia, pelo fato de esses assuntos estarem vivos e de o público ser particularmente sensível a eles. A epopeia é, para usar os termos de Florence Goyet (2006), essa "máquina de pensar" que os ouvintes integram e a partir da qual uma ideologia é construída. O que pode ser mais eficiente, para a consecução desse objetivo, do que uma rádio nacional que o propague amplamente?

Referências bibliográficas

BORNAND, Sandra. Le Discours du griot généalogiste chez les Zarma du Niger. Paris : Karthala, 2005.

BORNAND, Sandra. Hommage aux Peuls ou comment dire l'indicible en pays zarma. In : U. BAUMGARD, U. ; DERIVE, J. (éd.) Paroles nomades. Ecrits d'ethnolinguistique africaine. Paris : Karthala, 2005, p. 319-340.

BORNAND, Sandra. Parlons zarma. Une langue du Niger. Paris : L'Harmattan, 2016 ( $1^{\text {ère }}$ édition : 2006).

BORNAND, Sandra. Appeler les ancêtres : pratiques et mémoire discursive chez les Zarma du Niger. In : Textuel 56, 2009, p. 107-137.

BORNAND, Sandra. Une narration à deux voix. Exemple de coénonciation chez les jasare songhay-zarma du Niger. In : Cahiers de littérature orale 65 "Autour de la performance", 2009, p. 39-63. Mis en ligne le 01 mars 2013, consulté le 11 décembre 2016, http://clo.revues.org/1104.

BRIGAGLIA, Adera. The Radio Kaduna Tafse (1978-1992) and the Construction of public images of Muslim scholars in the Nigerian media. In: Journal for Islamic Studies 27, 2007, p. 173-210.

DECALO, Samuel. African Historical Dictionary of Niger. New York, London: African Historical Dictionaries 20, The Scarecraw Press, Inc. Metucken, 1979.

GADO BOUBE. Le Zarmatarey. Contribution à l'histoire des populations d'entre Niger et Dallol Mawri. Niamey : Études nigériennes 45, 1980.

GOYET, Florence. Penser sans concepts : fonctions de l'épopée guerrière. Iliade, Chanson de Roland, Hôgen et Heiji monogatari. Paris : Champion, 2006.

GREGOIRE, Emmanuel. Touaregs du Niger. Le destin d'un mythe [1981]. Paris : Karthala, 2010.

Idrissa, Kimba, Guerres et sociétés. Les populations du 'Niger' occidental au XIXe siècle et leurs réactions face à la colonisation (1896-1906), Niamey, Études nigériennes 46, 1981.

Komlavi Hahonou, Eric, "Culture politique, esclavage et décentralisation. La revanche politique des descendants d'esclaves au Bénin et au Niger", Politique Africaine 111, 2008, p. 169-186.

Mounkaïla, Fatimata, Mythe et histoire dans la geste de Zabarkane, Niamey, CEHLTO, 1989.

O’Brien, Susan M., "La charia contestée : démocratie, débat et diversité musulmane dans les "États charia" du Nigeria", La politique africaine : théories et pratiques 49, 1981.

Olivier de Sardan, Jean-Pierre, Concepts et conceptions songhay-zarma. Histoire culture société, Paris, Nubia, 1982. 
OLIVIER DE SARDAN, Jean-Pierre. Les Sociétés songhay-zarma (Niger, Mali). Chefs, guerriers, esclaves, paysans. Paris : Karthala, 1984.

OLIVIER DE SARDAN, Jean-Pierre. Unité et diversité de l'ensemble songhay-zarma-dendi. In : Peuplement et Migrations. Actes du premier colloque international, 26-29 septembre 1995. Parakou, Niamey : CEHLTO, 2000, p. 75-98.

RAYNAUT, Claude et Robert Buitenhuijs (éd.). Le Niger: Chroniques d'un État, Politique Africaine 38, juin 1990.

ROUCH, Jean. La Religion et la magie songhay. Bruxelles : Institut de Sociologie Anthropologie sociale, Éditions de l'Université de Bruxelles, 1989.

SEYDOU, Christiane. L'épopée peule de Boûbou Ardo Galo. Héros et rebelle. Paris : Karthala, 2010.

SEYDOU, Christiane. Boûbou Ardo Galo, ou les vicissitudes d'un héros épique peul. In : Recueil ouvert, 2017.

SOUNAYE, Abdoullaye. La "discothèque" islamique : CD et DVD au cœur de la réislamisation. In : Ethnographiques.org 22, 2011, en ligne : http://www.ethnographiques.org/2011/Sounaye.

SOUNAYE, Abdoullaye. L'Islam au Niger : éviter l'amalgame. In : L'Humanitaire 28, 2011, en ligne : http://humanitaire.revues.org/index1023.

VAN WALRAVEN, Klaas (traduction Alice Judell). Opération Somme : La French Connection et le coup d'État de Seyni Kountché au Niger en avril 1974. In : Politique Africaine 134, 2014, p. $133-$ 154. 